\title{
PFKFB4 Promotes Breast Cancer Metastasis via Induction of Hyaluronan Production in a p38-Dependent Manner
}

\author{
Ruifang Gao ${ }^{\mathrm{a}}$ Yanhua Liu ${ }^{\mathrm{a}}$ Dan Li ${ }^{\mathrm{a}} \quad$ Jing Xun ${ }^{\mathrm{a}}$ Wei Zhou ${ }^{\mathrm{a}}$ Peng Wang \\ Chen Liu ${ }^{b}$ Xiru Lic Wenzhi Shen ${ }^{d}$ Weijun Su ${ }^{a}$ Huan Qiao ${ }^{e}$ Dwayne G. Stupack ${ }^{f}$ \\ $\mathrm{Na}$ LuO $^{\mathrm{a}, \mathrm{g}, \mathrm{h}}$

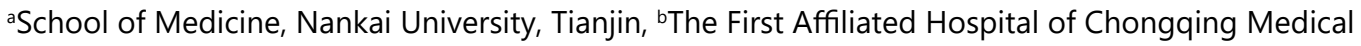 \\ University, Chongqing, 'Department of Surgery, Chinese PLA General Hospital, Beijing, dDepartment \\ of Pathology and Institute of Precision Medicine, Jining Medical University, Jining, China, ${ }^{\text {DDepartment }}$ \\ of Medicine, Vanderbilt University Medical Center, Nashville, 'Department of Reproductive Medicine, \\ School of Medicine and Moores Cancer Center, University of California, San Diego, USA, 9Tianjin \\ Key Laboratory of Tumor Microenvironment and Neurovascular Regulation, Tianjin, h2011 Project \\ Collaborative Innovation Center for Biotherapy of Ministry of Education, Tianjin, China
}

\section{Key Words}

PFKFB4 • Breast cancer $•$ Hyaluronan $\bullet$ p38 $\cdot$ Metastasis

\begin{abstract}
Background/Aims: The bi-functional enzyme 6-phosphofructo-2-kinase/fructose-2, 6-biphosphatase-4 (PFKFB4) is highly expressed in many types of cancer and its requirement for tumor survival has been demonstrated in glioma, lung, and prostate cancers. However, whether PFKFB4 plays a role in the tumor metastasis remains uncertain. This study explores the role of PFKFB4 in tumor metastasis and its underlying mechanisms in breast cancer cells. Methods: The expression of PFKFB4 was first analyzed using the Cancer Genome Atlas (TCGA) dataset, and confirmed by immunohistochemical staining of tissue microarray and breast cancer tissues from patient samples. Gain- and loss-of- function approaches were used to investigate the effects of PFKFB4 on breast cancer cell migration in vitro. Orthotopic xenograft model and experimental metastasis model were used to assess the effects of PFKFB4 on breast cancer cell metastasis in vivo. ELISA and immunofluorescence staining were used to examine HA production. Quantitative RT-PCR and western blotting were used to explore the mRNA and protein levels of HAS2, respectively. Results: We found that PFKFB4 enhances the migration/invasiveness of breast cancer cells in vitro as well as in vivo. Notably, the effects of PFKFB4 on migration are mediated by induction of HAS2 expression and HA production. Moreover, PFKFB4-induced HAS2 up-regulation depends upon the activation of p38 signaling.
\end{abstract}

R. Gao and Y. Liu contributed equally to this work.

\begin{tabular}{ll}
\hline Prof. Na Luo & School of Medicine, Nankai University, 94 Weijin Road, Tianjin 300071 (China) \\
and Prof. Dwayne G. Stupack & Dpt. of Reproductive Med., School of Med. and Moores Cancer Center, Univ. of CA, San Diego (USA), \\
& Tel. (086) 022-23509482, Fax (086) 022-23509482, E-Mail luon11@nankai.edu.cn; dstupack@ucsd.edu
\end{tabular}




\section{Cellular Physiology Cell Physiol Biochem 2018;50:2108-2123 and BiOChemistry Published onlıne: 10 November $2018 \begin{aligned} & \text { ㅇ } 2018 \text { The Author(s). Published by S. Karger AG, Basel } \\ & \text { www.karger.com/cpb }\end{aligned}$ \\ Gao et al.: PFKFB4 Promotes Breast Cancer Metastasis}

Conclusion: PFKFB4 promotes the metastasis of breast cancer cells via induction of HAS2 expression and HA production in a p38-dependent manner. Therefore, the PFKFB4/p38/HAS2 signaling pathway may serve as a potential therapeutic target for metastatic breast cancer.

(C) 2018 The Author(s)

Published by S. Karger AG, Basel

\section{Introduction}

Breast cancer is one of the most common types of cancer diagnosed among women world-wide and the second leading cause of cancer death among women in the US [1]. The high mortality rate associated with breast cancer probably results from its propensity to rapidly spread to other organs through lymphatic and blood vessels in spite of proper treatment [2-5].

Hypoxia is a common feature of many solid tumors and is linked to malignant transformation, metastasis, and treatment resistance [6]. Hypoxia causes important adaptations which include the activation of glycolysis-related genes that fulfill the energy demands of the tumor and provide a growth advantage [7]. Non-malignant cells use the TCA cycle and oxidative phosphorylation as their main source of ATP when oxygen is readily available. However, malignant cells use glycolysis as their primary energy source, even in oxygen rich conditions $[8,9]$. This persistent utilization of glycolysis serves as a hallmark of many cancers and is known as the Warburg effect [10].

Fructose-2, 6-bisphosphate acts as both the major allosteric regulator of 6-phosphofructo-1-kinase (a key regulatory enzyme of glycolysis) and as an inhibitor of fructose-1, 6-bisphosphatase [11-13]. The family of bi-functional 6-phosphofructo-2kinase/fructose-2, 6-bisphosphatase (PFKFB) enzymes maintains the cellular levels of fructose-2, 6-bisphosphate by synthesizing or degrading fructose-2, 6-bisphosphate along with controlling glycolysis [14]. The PFKFB family contains four isozymes encoded by four different genes (PFKFB1, PFKFB2, PFKFB3, and PFKFB4) that are located on different chromosomes. These PFKFB isozymes differ in their tissue distribution, kinetic activity, and regulatory properties. The human PFKFB4 gene is located on chromosome 3 (bands p21-p22) and encodes an isoenzyme originally detected in the testes $[15,16]$. PFKFB4 is not only induced by hypoxia in multiple cancer cell lines, but also is overexpressed in matched human lung, breast and colon tumor tissues compared to normal tissues from the same patients [17-20]. In addition, PFKFB4 is required for tumor survival in glioma, lung, and prostate cancers [21-23]. However, the impact of PFKFB4 on tumor metastasis which involves a complex and multistep process involving cell migration, adhesion, and survival remains unknown.

Hyaluronan (HA) is an evolutionarily conserved linear glycosaminoglycan with disaccharide repeats of D-glucuronic acid and N-acetyl-D-glucosamine that is synthesized on the cell membrane. HA is present in the extracellular matrix (ECM), on the cell surface, and within the cytoplasm [24]. HA synthesis is performed by a group of membrane-associated enzymes called HA synthase (HAS) [25]. There are three well-conserved HAS: HAS1, HAS2, and HAS3 [26]. HAS2 produces HA in tumors particularly the high molecular weight forms of HA (HMW-HA) in a prolific fashion [27]. HA catabolism is performed by a group of enzymes called hyaluronidase (HAase). There are two common and ubiquitously important HAase: Hyal1 and Hyal2 [28].

HA levels increase in many types of tumors which may elicit tumor metastasis and the alteration of the tumor microenvironment [29]. HAS up-regulation results in HA production within tumor tissues and thereby creates a pro-metastatic microenvironment [30]. In this regard, HAS2 up-regulation correlates with the metastasis of oral cancer cells, fibrosarcoma cells, ovarian cancer cells, osteosarcoma cells, and melanoma cells [31-35].

This study explored the role of PFKFB4 in tumor metastasis and its underlying mechanisms in breast cancer cells. We found that PFKFB4 enhances breast cancer cell migration/invasiveness in vitro and in vivo by regulating HAS2 expression and HA production. Moreover, the HAS2 up-regulation induced by PFKFB4 depends on the activation of p38 signaling. 


\section{Cellular Physiology Cell Physiol Biochem 2018;50:2108-2123 and Biochemistry Published \begin{tabular}{l|l} 
DOI: 10.1159/000495055 & $\begin{array}{l}\text { @ } 2018 \text { The Author(s). Published by S. Karger AG, Basel } \\
\text { www.karger.com/cpb }\end{array}$
\end{tabular} \\ Gao et al.: PFKFB4 Promotes Breast Cancer Metastasis}

\section{Materials and Methods}

\section{Cell culture}

breast carcinoma cell lines MDA-MB-231 and T47D were cultured in high glucose Dulbecco's modified Eagle's medium (DMEM, Biological Industries, Israel) containing 10\% fetal bovine serum (Biological Industries, Israel) and $100 \mathrm{U} / \mathrm{ml}$ penicillin/streptomycin (Hyclone, Logan, UT). Cells were maintained at $37^{\circ} \mathrm{C}$ in a humidified atmosphere with $5 \% \mathrm{CO}_{2}$. If necessary, $10 \mu \mathrm{M}$ of SB203580 (Cell Signaling Technology, Danvers, MA) or $10 \mu \mathrm{M}$ of PD98059 (Sigma-Aldrich, St. Louis, MO) was added to the medium in order to inhibit p38 or ERK activities, respectively.

\section{Tumor specimens and tissue microarray}

Human breast cancer samples were obtained from the Chinese PLA General Hospital. All samples were invasive ductal carcinoma of the breast that were confirmed histologically. This study was approved by the institutional ethics committees of PLA General Hospital. Human breast cancer tissue array (BC081120c, Alenabio Company, Shanxi, China) includes 110 samples (100 human breast cancer samples and 10 normal samples).

Vector construction and establishment of stable cell lines

To construct the human PFKFB4 overexpression vector, DNA sequence encoding human PFKFB4 was PCR-amplified from human cDNA, using primers 5'-CGTCTAGAGCCA CCATGGCGTCCCCACGGGAATTG-3' and 5'-CGACGCGTTCACTGGTGAGCAGGCACCGTG-3' and cloned into the pLV-EF1 $\alpha$-MCS-IRES-Bsd plasmid (Biosettia, San Diego, CA). For gene silencing, shPFKFB4 DNA oligomers 5'- AAAAGCCCAACTCTC ATTGTCATGGTTGGATCCAACCATGACAATGAGAGTTGGGC-3' and 5'-AAAAGCTGGAGAGGCAAGAGAATGTTTGGATCCAAACATTCTCTTGCCTCTCCAGC -3'; shHAS2 DNA oligomers 5'-AAAAGCATTGTGAGAGGTTTCTATGTTGGATCCAACATAGAAACCTCTCACAC- 3' were annealed and cloned into pLV-H1-EF1 $\alpha$-puro vector (Biosettia, San Diego, CA). The lentiviruses carrying the overexpression vectors, gene silencing vectors or empty vectors were produced according to manufacture's instruction. Lentivirus-containing medium was applied to cells in the presence of $8 \mu \mathrm{g} / \mathrm{ml}$ polybrene for 2 days, prior to selection with $10 \mu \mathrm{g} / \mathrm{ml}$ blasticidin (Bsd) or $1 \mu \mathrm{g} / \mathrm{ml}$ puromycin (Puro) for a week to establish stable cell lines.

\section{Quantitative RT-PCR}

Total RNA was extracted using TRIZOL reagent (Invitrogen, Carlsbad, CA), and reverse transcribed into cDNA using the TransScript First-Strand cDNA Synthesis SuperMix Kit (TransGen Biotech, Beijing, China) according to manufacturer's recommendations. qPCR was performed on a CFXTM Real-Time Thermal cycler (Bio-Rad,Hercules,CA) usingaTransStartTopGreenqPCRSupperMixkit(TransGenBiotech,Beijing,China).The primers used were as follows: HAS2, 5'-TGACAGGCATCTCACGAACC-3', and 5' - GGGTCTGCTGGTTTAGCCAT-3'; GAPDH, 5'-CTCTGATTTGGTCGTATTGGG-3', and 5'-TGGAAGATGGTGATGGGATT-3'.

\section{Western blotting}

Cells were washed in cold phosphate-buffered saline, collected and lysed in 1× RIPA buffer (50 mM Tris pH 7.4, $150 \mathrm{mM} \mathrm{NaCl}, 1.0 \%$ NP-40, 0.5\% Deoxycholic Acid, 0.1\% SDS, 1 mM EDTA, 1 mM EGTA, 5 $\mathrm{mM}$ sodium pyrophosphate, $50 \mathrm{mM} \mathrm{NaF}, 10 \mathrm{mM}$ b-glycerophosphate) with added phosphatase inhibitors (PhosSTOP, Roche Diagnostics, Vilvoorde, Belgium) and protease inhibitors (cOmplete, Roche Diagnostics, Vilvoorde, Belgium) for $30 \mathrm{~min}$ on ice. Lysates was centrifuged at 13, $000 \mathrm{rpm}$ for $15 \mathrm{~min}$ at $4^{\circ} \mathrm{C}$. Protein concentrations of the lysates were determined by BCA assay (Thermo Fisher Scientific, Waltham, MA). Samples were separated by $10 \%$ SDS-PAGE and transferred to nitrocellulose membranes. Membranes were blocked with $5 \%$ non-fat dry milk or 5\% BSA in tris-buffered saline (TBS) with $0.1 \%$ Tween-20 for $1 \mathrm{~h}$ at room temperature and then incubated overnight at $4{ }^{\circ} \mathrm{C}$ with the appropriate antibody in blocking buffer as indicated. Following incubation with appropriate horseradish peroxidase-conjugated secondary antibodies, proteins were visualized using an enhanced chemiluminescence detection system (Thermo Fisher Scientific, Waltham, MA). This study was performed using the following antibodies: $\beta$-actin (sc-47778), STAT3 (sc8019), p-STAT3 (sc-8001-R), p-ERK (sc-7976-R) and p-AKT (sc-135650), all of which were purchased from Santa Cruz Biotechnology. PFKFB4 (ab137785), HAS2 (ab199794), P38 (ab32142) and p-P38 (ab4822), all of which were purchased from Abcam. AKT (ZS-16190) and ERK (ZS-940), both of which were purchased from ZSGB-BIO. 


\section{Cellular Physiology Cell Physiol Biochem 2018;50:2108-2123 and Biochemistry Published \begin{tabular}{l|l} 
DOI: 10.1159/000495055 & $\begin{array}{l}\text { @ } 2018 \text { The Author(s). Published by S. Karger AG, Basel } \\
\text { www.karger.com/cpb }\end{array}$
\end{tabular} \\ Gao et al.: PFKFB4 Promotes Breast Cancer Metastasis}

\section{Transwell migration assay}

About $1 \times 10^{5}$ cells were seeded into the top transwell chamber ( $8 \mu \mathrm{m}$ pore size, 24 well plate) in $200 \mu \mathrm{l}$ medium containing $1 \% \mathrm{FBS}$. The bottom chamber contained $500 \mu \mathrm{l}$ medium containing $10 \% \mathrm{FBS}$. After $3 \mathrm{~h}$ (MDA-MB-231) or $48 \mathrm{~h}$ (T47D), the inserts were fixed with $4 \%$ paraformaldehyde and stained with crystal violet staining solution. Non-migrated cells were removed from top of the chamber with cotton swabs and bright-field photographs were taken using an OLYMPUS microscope (Olympus Co., Tokyo, Japan). Migrated cells of 5 random chosen areas were counted.

\section{Wound healing ass}

About $5 \times 10^{5}$ cells were seeded onto a 6-well plate in the presence of complete medium. Wound were generated by a conventional pipette tip when cells become confluent. The floating cells were aspirated and fresh media (1\% FBS) was added to the cells. Images were taken immediately and at $24 \mathrm{~h}$ (MDA-MB-231) or $48 \mathrm{~h}$ (T47D) post-wound. Migration distance was determined using the Image J software as an average of closed area relative to the initial wound area.

\section{Immunohistochemisty}

Paraffin-embedded sections of human breast cancer tissues and tissue array were deparaffinized and antigen retrieval performed using citrate buffer $(\mathrm{pH}=6)$ or Tris EDTA buffer $(\mathrm{pH}=9)$, at a temperature of $97^{\circ} \mathrm{C}$ for $20 \mathrm{~min}$. After exhaustion of endogenous peroxidase with methanol and hydrogen peroxide, slides were blocked with $0.3 \% \mathrm{BSA}$ in $0.1 \mathrm{~mol} / \mathrm{L}$ of tris-buffered saline for $30 \mathrm{~min}$ at room temperature, and incubated with primary antibody against PFKFB4 (Abcam, Cambridge, UK) overnight at $4^{\circ} \mathrm{C}$. Antibody binding was detected using a peroxidase-conjugated secondary antibody at $37^{\circ} \mathrm{C}$ for $30 \mathrm{~min}$. A DAB Substrate Kit was used to perform the chromogenic reaction. PFKFB4 expression levels in human breast tissues and tissue array were scored according to the extent of PFKFB4-positive cells and the staining intensity of each breast tissue sample. Specifically, 0-25\%, 26-50\%, 51-75\%, and 76-100\% were scored as 1, 2, 3 and 4, respectively. Tissues with brown, light brown, intermediate brown, and dark brown staining intensities were scored as $1,2,3$, and 4, respectively. Five random fields ( $\times 20$ magnification) were evaluated under a light microscope. The final scores were calculated by multiplying the scores of the intensity with those of the extent.

HA Assay

About $3 \times 10^{5}$ cells were seeded onto a 6-well plate in the presence of complete medium. After $48 \mathrm{~h}$, the conditioned medium was collected for HA content quantification using the Hyaluronan DuoSet kit (R\&D Systems, Abingdon, UK). HA concentration was calculated from a standard curve of the measured absorbance.

\section{HABP Staining}

Cells seeded on coverslips were washed once with PBS and fixed with $4 \%$ formaldehyde for $5 \mathrm{~min}$. Cells were incubated with $2 \mu \mathrm{g} / \mathrm{ml} \mathrm{HA}$ binding protein (HABP; Seikagaku, Japan) at room temperature for $1 \mathrm{~h}$ and incubated with $1 \mu \mathrm{g} / \mathrm{ml}$ FITC-conjugated streptavidin (Vector Laboratories, Burlingame, CA) for 30 min. Nuclei were counterstained with DAPI (Sigma-Aldrich, St. Louis, MO). Finally, sections were mounted with ProLongTM Gold antifade reagent (Thermo Fisher Scientific, Waltham, MA) and images were acquired by using a laser scanning confocal microscope (Leica, Wetzlar, Germany). The fluorescence intensity was quantified using ImageJ software.

\section{In vivo evaluation of Lung Metastasis}

To evaluate the lung metastasis, two types of mouse models were used. For the orthotopic model, PFKFB4-deficient or control MDA-MB-231 cells $\left(1 \times 10^{6}\right.$ in $100 \mu \mathrm{l}$ basic DMEM) were injected into the second mammary fat pad of 8-week-old female NOD/ SCID mice ( $\mathrm{n}=5$ per group). Tumor volume was measured twice a week. The mice were sacrificed 2 months after injection. Tumor weight was measured, and the lung was embedded in paraffin and sliced for HE staining to examine metastasis. For the experimental metastasis model, PFKFB4-expressing or control T47D cells $\left(2 \times 10^{6}\right.$ in $100 \mu \mathrm{l}$ basic DMEM) were injected into 8-weekold female NOD/SCID mice via the tail vein ( $\mathrm{n}=5$ per group). Mice were sacrificed 30 days after tail vein injection, and the lung were embedded in paraffin and sliced for HE staining to examine metastasis. Animal use complied with Nankai University Animal Welfare Guidelines.

\section{TCGA data analysis}

The data of 1098 patients with breast invasive carcinoma and 117 human normal tissues were downloaded from TCGA website (TCGA-BRCA). The normalized counts of the RNA expression of PFKFB4 were extracted and analysed.

\section{KARGER}




\section{Cellular Physiology Cell Physiol Biochem 2018;50:2108-2123 \begin{tabular}{ll|l} 
and BiOchemistry & $\begin{array}{l}\text { DOI: 10.1159/000495055 } \\
\text { Published onlıne: 10 November } 2018\end{array}$ & $\begin{array}{l}\text { (c) } 2018 \text { The Author(s). Published by S. Karger AG, Basel } \\
\text { www.karger.com/cpb }\end{array}$ \\
\hline
\end{tabular} \\ Gao et al.: PFKFB4 Promotes Breast Cancer Metastasis}

\section{Statistical analysis}

All data were analyzed using GraphPad Prism5 software (GraphPad Software, San Diego, CA). Results are presented as the mean \pm SD with the exception of human samples and animal model data, which are presented as mean \pm SEM. Statistical significance was determined by the Student's $t$-test or one-way ANOVA.

\section{Results}

\section{PFKFB4 expression increases in breast cancer tissues}

In order to determine PFKFB4 expression levels in breast cancer, we analyzed TCGA data of human breast cancer which included 1098 human breast cancer samples and 117 normal samples. This data analysis indicated that PFKFB4 expression increases in human breast cancer tissues versus normal breast tissues (Fig. 1a). To confirm the above-mentioned data analysis, we immunocytochemically-stained a microarray containing 100 human breast cancer samples and 10 normal samples for PFKFB4 expression. The microarray results confirmed that PFKFB4 expression increases in human breast cancer tissues (even in early stages of the cancer) versus normal breast tissue (Fig. 1b, c). In order to further validate

Fig. 1. PFKFB4 expression is increased in human breast cancer tissues. (a) The PFKFB4 mRNA levels in human breast tumor tissues and normal tissues from TCGA dataset (including 1098 human breast cancer samples and 117 normal samples). This graph shows that the relative PFKFB4 mRNA levels significantly increase in malignant tumors versus normal tissue $\quad(2.26 \pm 0.05$ vs $\quad 0.94 \pm 0.04$, respectively; $\quad * * * \mathrm{P}<$ 0.001). (b) PFKFB4 immunocytochemical staining of human

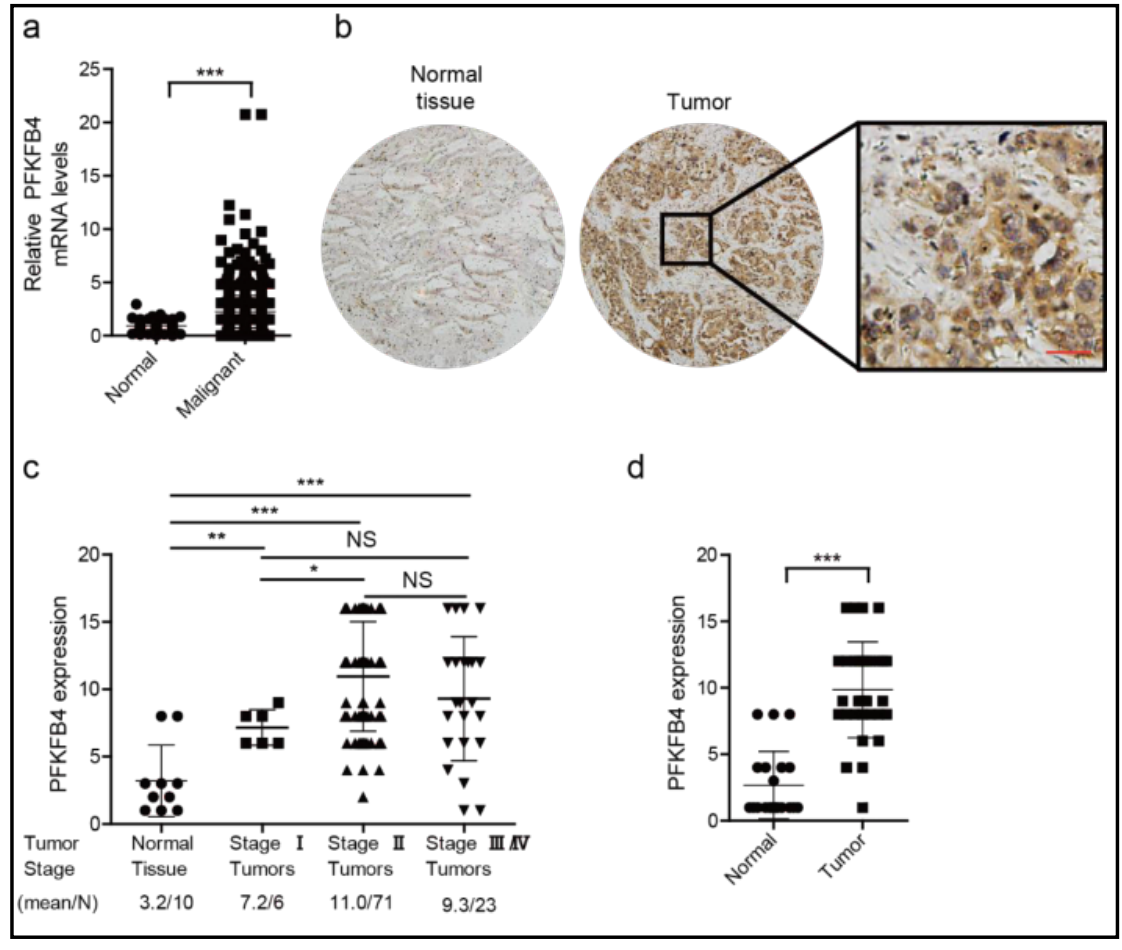
breast tissue

microarrays (including 100 human breast cancer samples and 10 normal samples). The representative micrographs qualitatively show the increase in PFKFB4 immunocytochemical staining in the tumor versus normal tissue. Scale bar $=100 \mu \mathrm{m}$. (c) Quantification of PFKFB4 expression based on PFKFB4 immunocytochemical staining of human breast tissue microarrays (from 1b). This graph quantitatively shows that PFKFB4 expression increases in Stage I tumors versus normal tissue $(7.2 \pm 0.54$ vs $3.2 \pm 0.84$, respectively; $\left.{ }^{* *} \mathrm{P}<0.01\right)$, in Stage II tumors versus normal tissue $\left(11.0 \pm 0.48\right.$ vs $3.2 \pm 0.84$, respectively; ${ }^{* * *} \mathrm{P}<$ $0.001)$, and in Stage III/IV tumors versus normal tissue $\left(9.3 \pm 0.96\right.$ vs $3.2 \pm 0.84$, respectively; $\left.{ }^{* * *} \mathrm{P}<0.001\right)$. In addition, PFKFB4 expression increases in Stage II tumors versus Stage I tumors $(11.0 \pm 0.48$ vs $7.2 \pm 0.54$, respectively; $\left.{ }^{*} \mathrm{P}<0.05\right)$. However, $\mathrm{PFKFB} 4$ expression does not increase in Stage II tumors versus Stage III/IV tumors ( $11.0 \pm 0.48$ vs $9.3 \pm 0.96$, respectively; NS). The mean values of each group and the number of samples are listed below the $x$ axis. (d) Quantification of PFKFB4 expression based on PFKFB4 immunocytochemical staining in tumor $(n=32)$ or peri-tumor tissue $(n=21)$ of breast cancer patients. This graph quantitatively shows that PFKFB4 expression increases in human breast cancer tumors versus normal tissue $(9.84 \pm 0.64$ vs $2.67 \pm 0.55$, respectively; $\left.{ }^{* * *} \mathrm{P}<0.001\right)$. Data are shown as mean $\pm \mathrm{SEM}$; Student's t-test was used for statistical analysis except for Fig. 1c (one-way ANOVA); NS= not significant. 


\section{Cellular Physiology Cell Physiol Biochem 2018;50:2108-2123

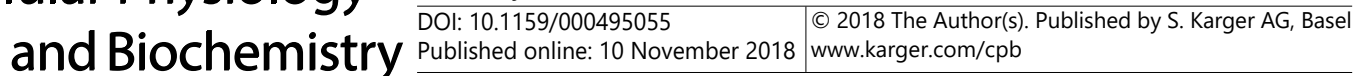 \\ Gao et al.: PFKFB4 Promotes Breast Cancer Metastasis}

the above findings, we immunocytochemically-stained biopsies from breast cancer patients which included 32 breast cancer tissues and 21 peri-tumor tissues. The results again indicated that PFKFB4 expression increases in breast cancer tissues (Fig. 1d).

\section{PFKFB4 promotes the migration of breast cancer cells in vitro}

In order to investigate the function of PFKFB4 on the migration of breast cancer cells, we stably knocked down PFKFB4 in MDA-MB-231 breast cancer cells and measured migration by the transwell assay and the razor-wound assay. The results showed that PFKFB4 knockdown significantly decreases the migration of MDA-MB-231 breast cancer cells in both assays (Fig. 2a-c). Similar results were observed with the T47D breast cancer cells (Fig. 2d-f). To further confirm the role that PFKFB4 plays on the migration of breast cancer cells, we next ectopically expressed PFKFB4 in MDA-MB-231 breast cancer cells and measured migration by the transwell assay and the razor-wound assay. The results showed that PFKFB4 ectopic expression increases the migration of MDA-MB-231 breast cancer cells

Fig. 2. Suppression of PFKFB4 inhibits the migration/ invasion of breast cancer cells in vitro. (a) Western blot analysis of PFKFB4 expression. This western blot qualitatively shows that PFKFB4 expression decreases in PFKFB4 knockdown (PFKFB4-sh1 and PFKFB4-sh2) MDAMB-231 cells versus vector controls (SC). $\beta$-actin serves as a loading control. (b) Transwell assay of migrated cells. This graph shows that the number of migrated cells decreases in PFKFB4 knockdown (PFKFB4-sh1 and

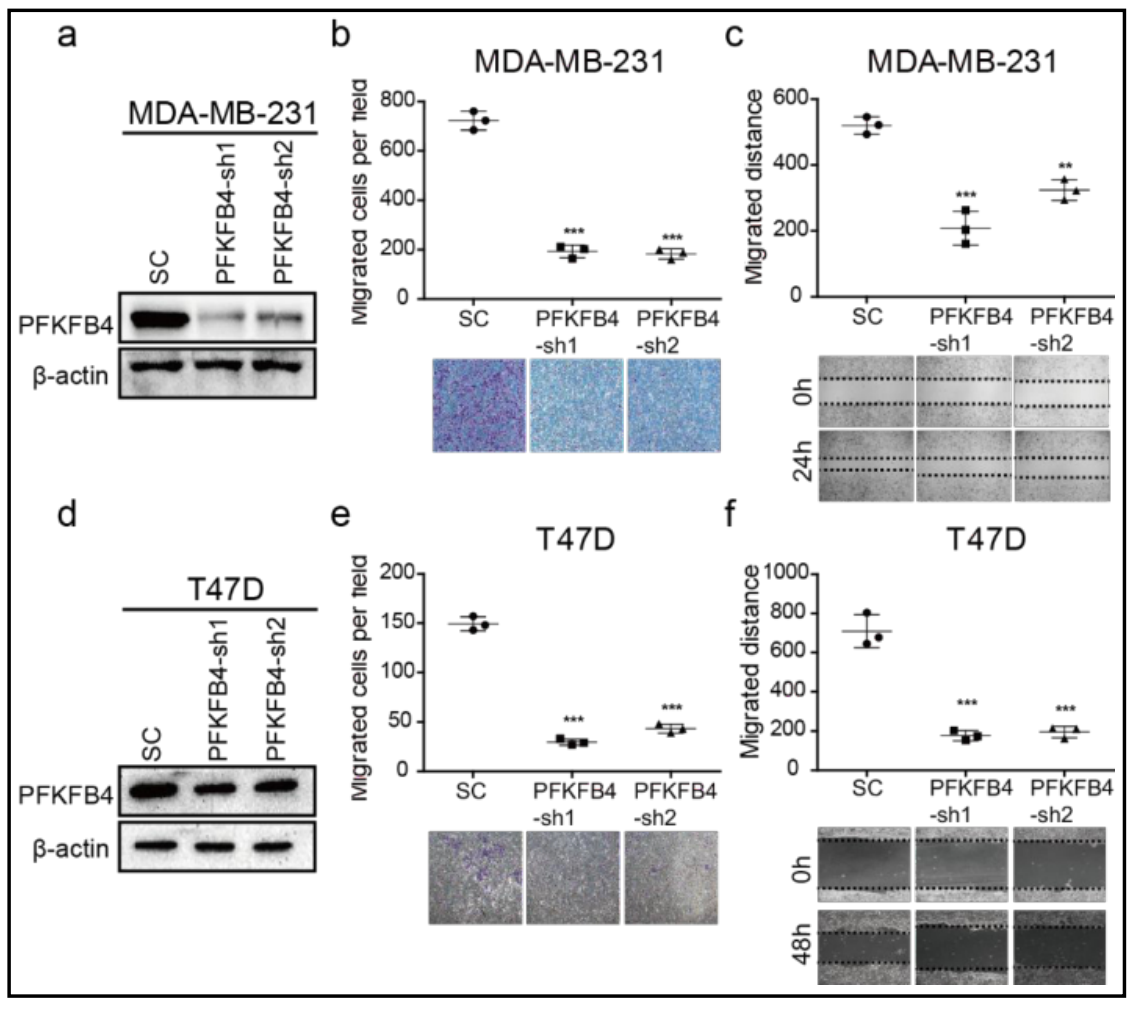
PFKFB4-sh2) MDA-MB-231 cells versus vector controls (SC) $(193 \pm 26,183 \pm 21$ vs $722 \pm 38$, respectively; $* * * \mathrm{P}<0.001$ ). The representative graphs of each group are listed below the $\mathrm{x}$ axis. (c) Wound healing assay of migrated distance. This graph shows that the migrated distance decreases in PFKFB4 knockdown (PFKFB4-sh1 and PFKFB4-sh2) MDA-MB-231 cells versus vector controls (SC) (208.8 $\pm 51.0,324.3 \pm 31.6$ vs $520.3 \pm 26.3$, respectively; ${ }^{* * *} \mathrm{P}<0.001,{ }^{* *} \mathrm{P}<0.01$ ). The representative graphs of each group are listed below the $\mathrm{x}$ axis. (d) Western blot analysis of PFKFB4 expression. This western blot qualitatively shows that PFKFB4 expression decreases in PFKFB4 knockdown (PFKFB4-sh1 and PFKFB4-sh2) T47D cells versus vector controls (SC). $\beta$-actin serves as a loading control. (e) Transwell assay of migrated cells. This graph shows that the number of migrated cells decreases in PFKFB4 knockdown (PFKFB4-sh1 and PFKFB4-sh2) T47D cells versus vector controls (SC) $\left(30 \pm 3,43 \pm 5\right.$ vs $149 \pm 7$, respectively; $\left.{ }^{* * *} \mathrm{P}<0.001\right)$. The representative graphs of each group are listed below the $\mathrm{x}$ axis. (f) Wound healing assay of migrated distance. This graph shows that the migrated distance decreases in PFKFB4 knockdown (PFKFB4-sh1 and PFKFB4-sh2) T47D cells versus vector controls (SC) $\left(177.0 \pm 25.6,195.0 \pm 28.6\right.$ vs $709.0 \pm 83.9$, respectively; $\left.{ }^{* * *} \mathrm{P}<0.001\right)$. The representative graphs of each group are listed below the $\mathrm{x}$ axis. Data are shown as mean \pm SD; Student's t-test was used for statistical analysis except for Fig. 2b, c, e f (one-way ANOVA); Data are representatives of at least three independent experiments. 


\section{Cellular Physiology Cell Physiol Biochem 2018;50:2108-2123

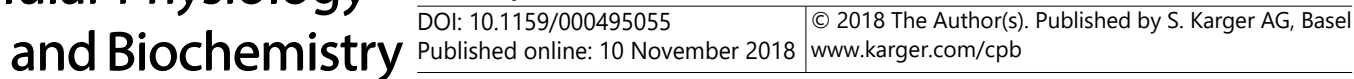

Fig. 3. Ectopic expression of PFKFB4 promotes the migration/invasion of breast cancer cells in vitro. (a) Western blot analysis of PFKFB4 expression. This western blot qualitatively shows that PFKFB4 expression increases in PFKFB4 ectopic expression (PFKFB4) MDA-MB-231 cells versus vector controls (MCS). $\beta$-actin serves as a loading control. (b) Transwell assay of migrated cells. This graph shows that the number of migrated cells increases in PFKFB4 MDAMB-231 cells versus vector controls (MCS) $(139 \pm 15$ vs $30 \pm 5$, respectively; ${ }^{* * *} \mathrm{P}<$ 0.001 ). The representative graphs of each group are listed below the $\mathrm{x}$ axis. (c) Wound healing assay of

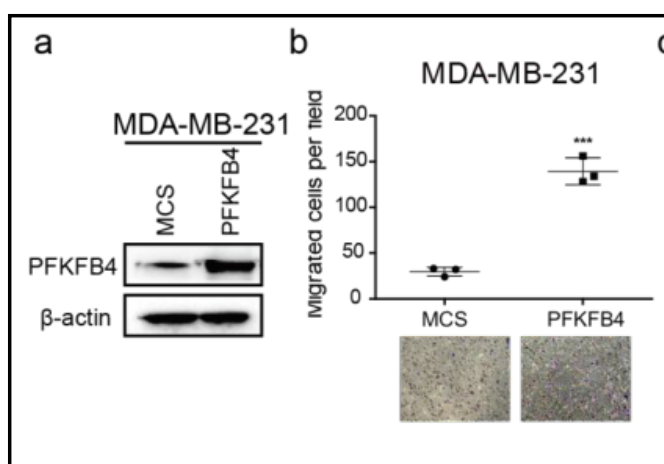

d

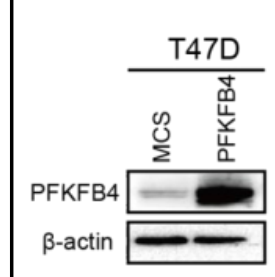

e

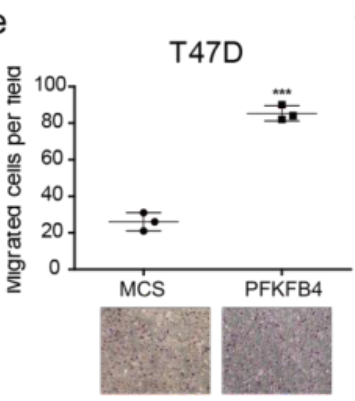

C
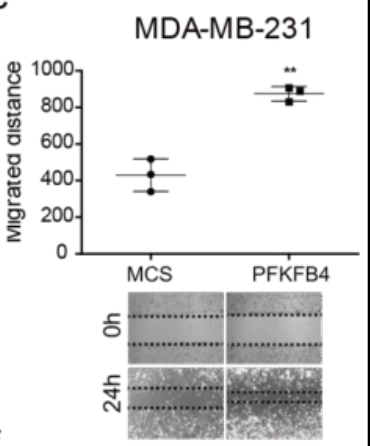

T47D

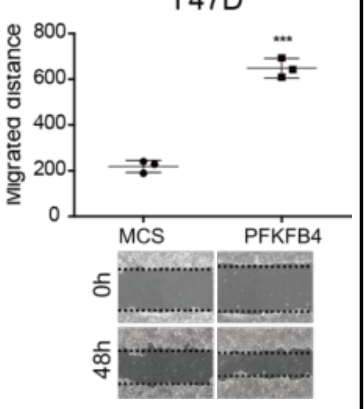
migrated distance. This graph shows that the migrated distance increases in PFKFB4 MDA-MB-231 cells versus vector controls (MCS) $\left(875.0 \pm 40.4\right.$ vs $430.5 \pm 89.3$, respectively; $\left.{ }^{* *} \mathrm{P}<0.01\right)$. The representative graphs of each group are listed below the $x$ axis. (d) Western blot analysis of PFKFB4 expression. This western blot qualitatively shows that PFKFB4 expression increases in PFKFB4 ectopic expression (PFKFB4) T47D cells versus vector controls (MCS). $\beta$-actin serves as a loading control. (e) Transwell assay of migrated cells. This graph shows that the number of migrated cells increases in PFKFB4 T47D cells versus vector controls (MCS) $\left(85 \pm 4\right.$ vs $26 \pm 5$, respectively; $\left.{ }^{* * *} \mathrm{P}<0.001\right)$. The representative graphs of each group are listed below the $\mathrm{x}$ axis. (f) Wound healing assay of migrated distance. This graph shows that the migrated distance increases in PFKFB4 T47D cells versus vector controls (MCS) (648.0 \pm 42.3 vs $219.0 \pm 26.7$, respectively; ${ }^{* * *} \mathrm{P}<0.001$ ). The representative graphs of each group are listed below the $\mathrm{x}$ axis. Data are shown as mean \pm SD; Student's t-test was used for statistical analysis; Data are representatives of at least three independent experiments.

in both assays (Fig. 3a-c). Similar results were observed with the T47D breast cancer cells (Fig. 3d-f). Our findings collectively support the notion that PFKFB4 promotes the migration of breast cancer cells in vitro.

\section{PFKFB4 promotes lung metastasis of breast cancer cells in vivo}

In order to evaluate the impact of PFKFB4 on tumor dissemination in vivo, we employed two metastasis mouse models, namely the orthotopic xenograft mouse model and experimental metastasis mouse model. In the orthotopic xenograft mouse model, PFKFB4deficient or control MDA-MB-231 breast cancer cells were injected into the second fat pad of immunodeficient NOD/SCID mice. We found that PFKFB4-deficient MDA-MB-231 breast cancer cells grow significantly smaller in terms of volume and weight versus control MDAMB-231 breast cancer cells (Fig. 4a, b). In addition, PFKFB4-deficient MDA-MB-231 breast cancer cells show a significantly decreased number of lung metastasis versus control MDAMB-231 breast cancer cells (Fig. 4c, d). In the experimental metastasis mouse model, PFKFB4ectopically expressed or control T47D breast cancer cells were injected into immunodeficient NOD/SCID mice via the tail vein. We found that PFKFB4-ectopically expressed T47D breast cancer cells show a significantly increased number of lung metastasis versus control T47D breast cancer cells (Fig. 4e, f). These observations collectively suggest that PFKFB4 plays a facilitative role in the metastasis of breast cancer cells in vivo. 


\section{Cellular Physiology Cell Physiol Biochem 2018;50:2108-2123

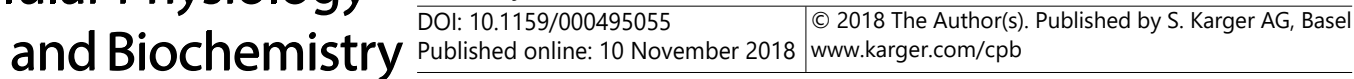

Fig. 4. PFKFB4 promotes the metastasis of breast cancer cells in vivo. (a) Tumor volume of MDA-MB-231 cells inoculated in the second fat pad of NOD/SCID mice, this graph shows that the tumor growth decreases in PFKFB4 knockdown (PFKFB4-sh) MDAMB-231 cells versus vector controls (SC) $(1434 \pm 85.28$ vs $773.4 \pm 94.14$, respectively; $\left.{ }^{* * *} \mathrm{P}<0.001\right), \mathrm{n}=5$. (b) Tumor weight of MDA-MB-231 cells inoculated in the second fat pad of NOD/SCID mice, this graph shows that the tumor weight decreases in PFKFB4 knockdown (PFKFB4-sh) MDA-MB-231 cells versus vector controls (SC) $(0.76 \pm 0.03$ vs $0.34 \pm 0.06$, respectively; $* * * \mathrm{P}<0.001$ ), $\mathrm{n}=5$. (c) Representative images of metastasis in the lung are shown. This graph qualitatively shows that the lung metastasis decreases in PFKFB4 knockdown (PFKFB4sh) MDA-MB-231 cells versus vector controls (SC). Scale bar $=25 \mu \mathrm{m}$. (d) Quantification of lung metastasis based on $H \& E$ staining in the lung sections (from 3c). This graph quantitatively shows that the lung metastasis decreases in PFKFB4 knockdown (PFKFB4-sh) MDA-MB-231 cells versus vector controls (SC) $(19.8 \pm 1.2$ vs $3.4 \pm 0.51$, respectively; ${ }^{* * *} \mathrm{P}<0.001$ ). (e) Representative images of metastasis in the lung via tail vein injection of T47D cells in NOD/SCID mice. This graph qualitatively shows that the lung metastasis increases in PFKFB4 ectopic expression (PFKFB4) T47D cells versus vector controls (MCS). Scale bar $=50 \mu \mathrm{m}$. (f) Quantification of lung metastasis based on H\&E staining in the lung sections (from 3e). This graph quantitatively shows that the lung metastasis increases in PFKFB4 T47D cells versus vector controls (MCS) (17.0 \pm 2.2 vs $2.8 \pm 0.73$, respectively; $\left.{ }^{* * *} \mathrm{P}<0.001\right)$. Data are shown as mean $\pm \mathrm{SEM}$; Student's t-test was used for statistical analysis.

\section{PFKFB4 increases HAS2 expression and HA production}

Considering that PFKFB4 functions in glucose metabolism and cell migration and that HA functions in cell motility, we next tested whether PFKFB4 affects HA production in MDAMB-231 and T47D breast cancer cells using the ELISA assay and immunofluorescence. Our results indicated that PFKFB4 ectopic expression in MDA-MB-231 and T47D breast cancer cells increases HA production versus controls (Fig. 5a-d). Since HAS2 synthesizes HA, we tested whether PFKFB4 influences HAS2 expression in MDA-MB-231 and T47D breast cancer cells by measuring both HAS2 mRNA and protein levels. Our results showed a downregulation of HAS2 expression in PFKFB4-deficient MDA-MB-231 and T47D cells versus controls (Fig. 6a, b). Conversely, our results showed an up-regulation of HAS2 expression in PFKFB4-ectopically expressed MDA-MB-231 and T47D cells versus controls (Fig. 6c, d). 
Fig. 5. PFKFB4 enhances HA production. (a) ELISA analysis of HA concentration in supernatant. This graph shows that HA production increases in PFKFB4 MDA-MB-231 cells versus vector controls (MCS) $(13.73 \pm 1.43$ vs $6.10 \pm 1.50$, respectively; ${ }^{* *} \mathrm{P}<0.01$ ). (b) Representative images of HA stained with HABP-FITC (left panel) and quantification (right panel). This graph shows that HA production increases in PFKFB4 MDA-MB-231 cells versus vector controls (MCS) $\quad(0.073 \pm 0.006$ vs $0.032 \pm 0.003$, respectively; $* * * \mathrm{P}<0.001$ ). (c) ELISA analysis of HA concentration in the supernatant. This graph shows that HA production increases in PFKFB4 T47D cells versus vector

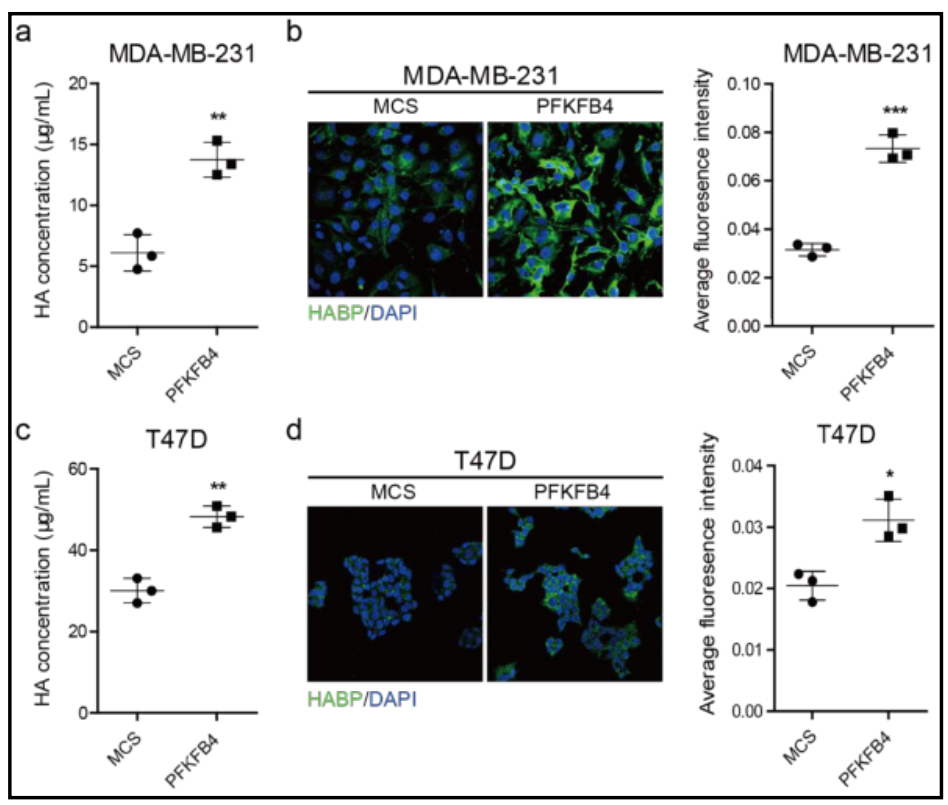
controls (MCS) $(48.27 \pm 2.65$ vs

$30.07 \pm 3.04$, respectively; ${ }^{* *} \mathrm{P}<0.01$ ). (d) Representative images of HA stained with HABP-FITC (left panel) and quantification (right panel). This graph shows that HA production increases in PFKFB4 T47D cells versus vector controls (MCS) $\left(0.031 \pm 0.003\right.$ vs $0.02 \pm 0.002$, respectively; $\left.{ }^{*} \mathrm{P}<0.05\right)$. Data are shown as mean \pm SD; Student's t-test was used for statistical analysis; Data are representatives of at least three independent experiments.

Fig. 6. PFKFB4 enhances HAS2 expression. Quantitative PCR (qPCR) of HAS2 mRNA expression. This graph quantitatively shows that relative HAS2 mRNA levels decreases in PFKFB4 knockdown (PFKFB4-sh1 and PFKFB4-sh2) MDA-MB-231 and T47D cells versus vector controls (SC) $\quad(0.63 \pm 0.07$, $0.48 \pm 0.04$ vs $0.98 \pm 0.08$, respectively; $\quad * * \mathrm{P}<0.01$, $* * * \mathrm{P}<0.001$ and $0.42 \pm 0.17$, $0.62 \pm 0.11$ vs $1.05 \pm 0.10$, respectively; $\quad * * \mathrm{P}<0.01$ ). (b) Western blot analysis of HAS2 expression. This western blot qualitatively shows that HAS2 expression decreases in PFKFB4 knockdown (PFKFB4sh1 and PFKFB4-sh2) MDAMB-231 and T47D cells versus

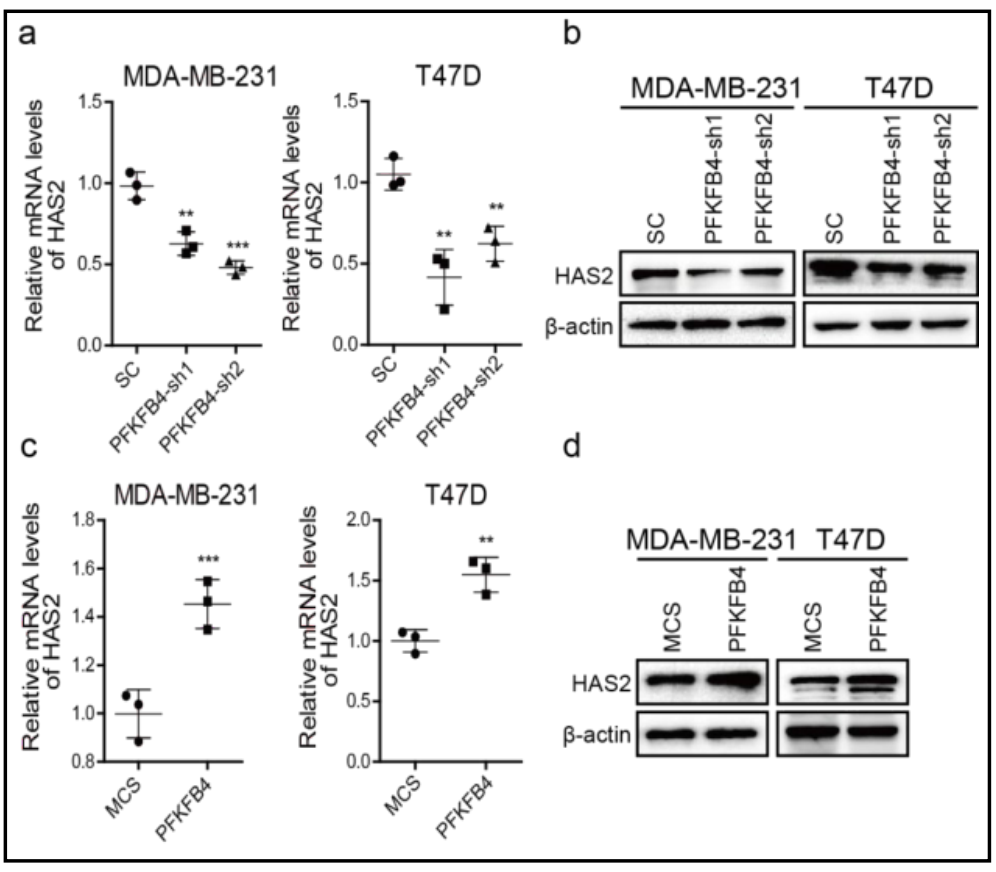
vector controls (SC). $\beta$-actin serves as a loading control. (c) qPCR of HAS2 mRNA expression. This graph quantitatively shows that relative HAS2 mRNA levels increases in PFKFB4 MDA-MB-231 and T47D cells versus vector controls (MCS) (1.5 \pm 0.1 vs $1.0 \pm 0.1$, respectively; ${ }^{* * *} \mathrm{P}<0.001$ and $1.55 \pm 0.14$ vs $1.0 \pm 0.09$, respectively; ${ }^{* *} \mathrm{P}<0.01$ ). (d) Western blot analysis of HAS2 expression. This western blot qualitatively shows that HAS2 expression increases in PFKFB4 MDA-MB-231 and T47D cells versus vector controls (MCS). $\beta$-actin serves as a loading control. Data are shown as mean \pm SD; One-way ANOVA was used for statistical analysis of Fig. 6 a, and Student's t-test was used for statistical analysis of Fig. 6c; Data are representatives of at least three independent experiments. 
Fig. 7. PFKFB4-mediated migration requires $\mathrm{HA}$ accumulation in breast cancer cells. (a) Transwell assay of migrated cells. This graph shows that in control group (HAase-), the number of migrated cells increases in PFKFB4 MDA-MB-231 cells versus MCS cells $(100 \pm 11$ vs $54 \pm 4$, respectively; $\left.{ }^{* *} \mathrm{P}<0.01\right)$. In the presence of HAase (HAase+), the number of migrated cells does not increase in PFKFB4 MDAMB-231 cells versus MCS cells $(31 \pm 4$ vs $27 \pm 3$, respectively; NS). (b) Wound healing assay of migrated distance. This graph shows that in control group (HAase-), the migrated distance increases in PFKFB4 MDA-MB-231 cells versus MCS cells $(467.0 \pm 10.8$ vs $206.7 \pm 7.1$, respectively; $\left.{ }^{* * *} \mathrm{P}<0.001\right)$. In the presence of HAase (HAase+), the migrated distance does not increase in PFKFB4 MDA-MB-231 cells versus MCS cells (114.4 \pm 8.5 vs 104.6 \pm 4.1 , respectively; NS). (c) Transwell assay of migrated cells. This graph shows that in control group (HAase-), the number of migrated cells increases in PFKFB4 T47D cells versus MCS cells $(110 \pm 10$ vs $58 \pm 9$, respectively; $\left.{ }^{* *} \mathrm{P}<0.01\right)$. In the presence of HAase (HAase+), the

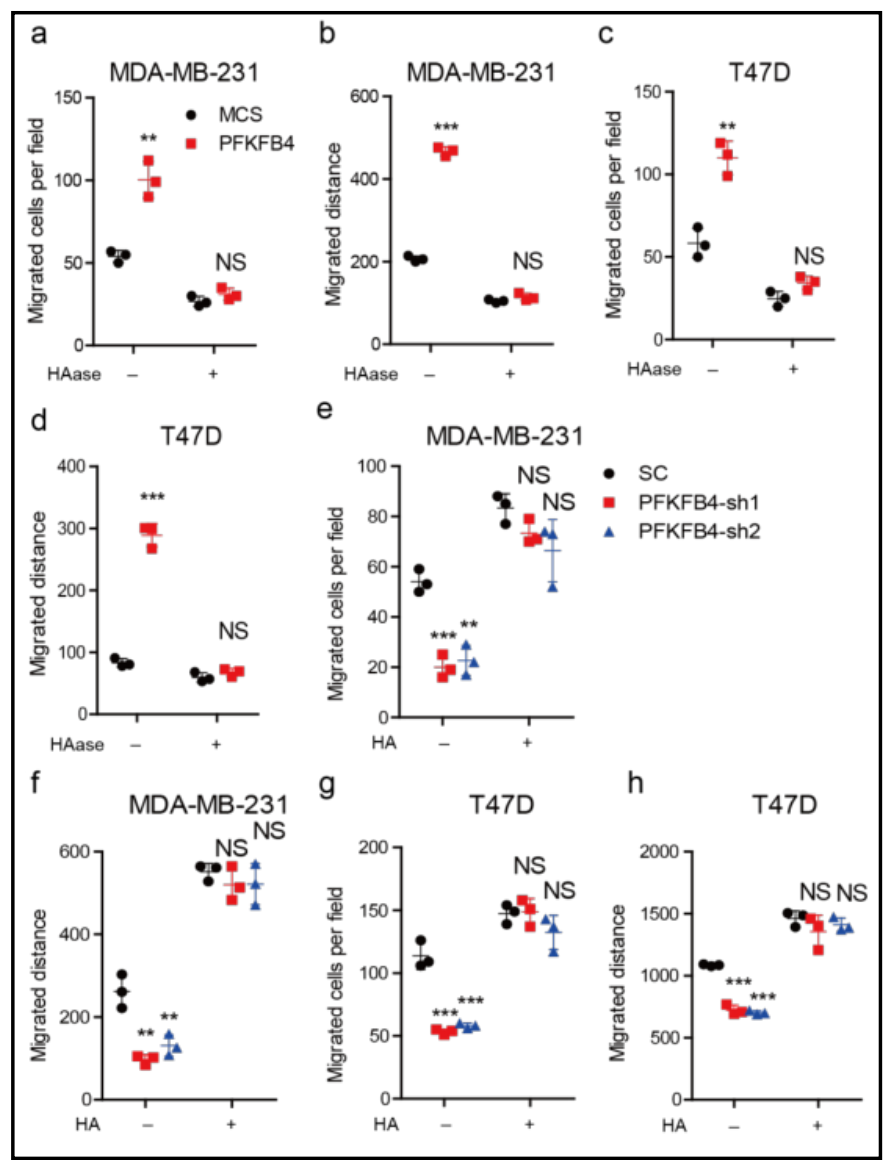
number of migrated cells does not

increase in PFKFB4 T47D cells versus MCS cells ( $34 \pm 4$ vs $25 \pm 5$, respectively; NS). (d) Wound healing assay of migrated distance. This graph shows that in control group (HAase-), the migrated distance increases in PFKFB4 T47D cells versus MCS cells $\left(289.0 \pm 18.6\right.$ vs $82.9 \pm 6.7$, respectively; $\left.{ }^{* * *} \mathrm{P}<0.001\right)$. In the presence of HAase (HAase+), the migrated distance does not increase in PFKFB4 T47D cells versus MCS cells $(67.6 \pm 6.3$ vs 59.4 \pm 7.6, respectively; NS). (e) Transwell assay of migrated cells. This graph shows that in control group (HA-), the number of migrated cells decreases in PFKFB4 knockdown (PFKFB4-sh1 and PFKFB4-sh2) MDAMB-231 cells versus SC cells $\left(20 \pm 5,23 \pm 6\right.$ vs $54 \pm 5$, respectively; $\left.{ }^{* *} \mathrm{P}<0.01,{ }^{* * *} \mathrm{P}<0.001\right)$. In the presence of $\mathrm{HA}(\mathrm{HA}+$ ), the number of migrated cells does not decrease in PFKFB4 knockdown (PFKFB4-sh1 and PFKFB4sh2) MDA-MB-231 cells versus SC cells $(73 \pm 5,66 \pm 12$ vs $83 \pm 6$, respectively; NS). (f) Wound healing assay of migrated distance. This graph shows in control group (HA-), the migrated distance decreases in PFKFB4 knockdown (PFKFB4-sh1 and PFKFB4-sh2) MDA-MB-231 cells versus SC cells $(97.0 \pm 11.4,131.0 \pm 25.9$ vs $262.0 \pm 40.5$, respectively; $\left.{ }^{* *} \mathrm{P}<0.01\right)$. In the presence of $\mathrm{HA}(\mathrm{HA}+)$, the migrated distance does not decrease in PFKFB4 knockdown (PFKFB4-sh1 and PFKFB4-sh2) MDA-MB-231 cells versus SC cells (520.0 \pm 41.0 , $521.0 \pm 50.0$ vs $551.0 \pm 20.0$, respectively; NS). (g) Transwell assay of migrated cells. This graph shows that in control group (HA-), the number of migrated cells decreases in PFKFB4 knockdown (PFKFB4-sh1 and PFKFB4-sh2) T47D cells versus SC cells $\left(53 \pm 2,58 \pm 2\right.$ vs $114 \pm 11$, respectively; $\left.{ }^{* * *} \mathrm{P}<0.001\right)$. In the presence of HA (HA+), the number of migrated cells does not decrease in PFKFB4 knockdown (PFKFB4-sh1 and PFKFB4-sh2) T47D cells versus SC cells $(149 \pm 11,132 \pm 14$ vs $147 \pm 8$, respectively; NS). (h) Wound healing assay of migrated distance. This graph shows in control group (HA-), the migrated distance decreases in PFKFB4 knockdown (PFKFB4-sh1 and PFKFB4-sh2) T47D cells versus SC cells $(723.0 \pm 40.0,703.0 \pm 15.4$ vs $1085 \pm 7.6$, respectively; $\left.{ }^{* * *} \mathrm{P}<0.001\right)$. In the presence of $\mathrm{HA}(\mathrm{HA}+)$, the migrated distance does not decrease in PFKFB4 knockdown (PFKFB4-sh1 and PFKFB4-sh2) T47D cells versus SC cells (1356 $\pm 131.6,1411 \pm 54.3$ vs $1461 \pm 60.1$, respectively; NS). Data are shown as mean \pm SD; One-way ANOVA was used for statistical analysis; NS= not significant; Data are representatives of at least three independent experiments. 
Fig. 8. PFKFB4-mediated migration requires HAS2 expression in breast cancer cells. (a) Transwell assay of migrated cells. This graph shows that in control group (SC), the number of migrated cells increases in PFKFB4 MDAMB-231 cells versus MCS cells ( $88 \pm 3$ vs $53 \pm 10$, respectively; ${ }^{* *} \mathrm{P}<0.01$ ). In HAS2 knockdown group (shHAS2), the number of migrated cells does not increase in PFKFB4 MDA-MB-231 cells versus MCS cells $(23 \pm 11$ vs $22 \pm 12$, respectively; NS). (b) Wound healing assay of migrated distance. This graph shows that in control group (SC), the migrated distance increases in PFKFB4 MDA-MB-231 cells versus MCS cells $(950.0 \pm 36.7$ vs $464.0 \pm 58.51$, respectively; ${ }^{* * *} \mathrm{P}<0.001$ ). In HAS2 knockdown group (shHAS2), the migrated distance does not increase in PFKFB4 MDAMB-231 cells versus MCS cells $(189.0 \pm 41.2$ vs

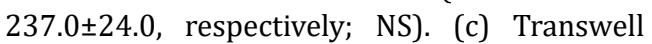
assay of migrated cells. This graph shows that in control group (SC), the number of migrated cells increases in PFKFB4 T47D cells versus MCS cells $\left(101 \pm 12\right.$ vs $25 \pm 3$, respectively; ${ }^{* *} \mathrm{P}<$ 0.01 ). In HAS2 knockdown group (shHAS2), the number of migrated cells does not increase in PFKFB4 T47D cells versus MCS cells $(24 \pm 7$ vs $22 \pm 3$, respectively; NS). (d) Wound healing assay of migrated distance. This graph shows that in control group (SC), the migrated distance increases in PFKFB4 T47D cells versus MCS cells (617.0 \pm 17.6 vs $273.0 \pm 70.9$, respectively; $\left.{ }^{* * *} \mathrm{P}<0.001\right)$. In HAS2 knockdown group (shHAS2), the migrated distance does not increase in PFKFB4 T47D cells versus MCS cells (191.0 \pm 27.2 vs $199.0 \pm 55.5$, respectively; NS). Data are shown as mean \pm SD; One-way ANOVA was used for statistical analysis; NS= not significant; Data are representatives of at least three independent experiments.

PFKFB4-mediated migration requires HAS2 expression and HA accumulation in breast cancer cells

In order to determine whether PFKFB4-mediated migration requires $\mathrm{HA}$, we administered hyaluronidase (HAase) to PFKFB4-ectopically expressed MDA-MB-231 and T47D cells and measured the number and distance of migrated cells. Our findings indicated that hyaluronidase administration eliminates the elevated migration capacity in PFKFB4ectopically expressed MDA-MB-231 and T47D cells versus controls (Fig. 7a-d). In order to further confirm the above finding, we administered exogenous HA to PFKFB4-deficient MDA-MB-231 and T47D cells and measured the number and distance of migrated cells. Our findings indicated that exogenous HA administration rescues the depressed migration capacity in PFKFB4-deficient MDA-MB-231 and T47D cells versus controls (Fig. 7e-h).

Finally, in order to determine whether PFKFB4-mediated migration requires HAS2, we silenced HAS2 expression in PFKFB4-ectopically expressed MDA-MB-231 and T47D cells and measured the number and distance of migrated cells. Our findings showed that HAS2 silencing eliminates the elevated migration capacity in PFKFB4-ectopically expressed MDAMB-231 and T47D cells versus controls (Fig. 8a-d). The above-mentioned findings collectively indicate that PFKFB4-mediated migration requires HAS2 and HA in breast cancer cells.

PFKFB4-induced HAS2 up-regulation and breast cancer cell migration depend on p38 phosphorylation

We next explored the underlying mechanism of HAS2 up-regulation induced by PFKFB4. Since ERK, p38, STAT3, and Akt signaling pathways regulate HAS2 expression, we therefore examined the effect of PFKFB4 ectopic expression on the phosphorylation of these signaling proteins in MDA-MB-231 and T47D breast cancer cells. We found that 


\section{Cellular Physiology Cell Physiol Biochem 2018;50:2108-2123

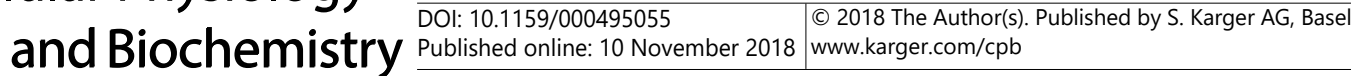

Fig. 9. PFKFB4-induced HAS2 up-regulation depends on p38 phosphorylation. (a) Western blot analysis of ERK, P38, STAT3 and AKT phosphorylation. This western blot qualitatively shows that the phosphorylation of ERK and P38 increases in PFKFB4 MDA-MB-231 and T47D cells versus vector controls (MCS), while the phosphorylation of STAT3 and AKT does not change. The total expression of ERK, P38, STAT3 and AKT does not change. $\beta$-actin serves as a loading control. (b) Western blot analysis of HAS2 expression. This western blot qualitatively shows that in control group (SB203580-), HAS2 expression increases in PFKFB4 MDA-MB-231 and T47D cells versus MCS cells. In the presence of P38 inhibitor SB203580 (SB203580+),

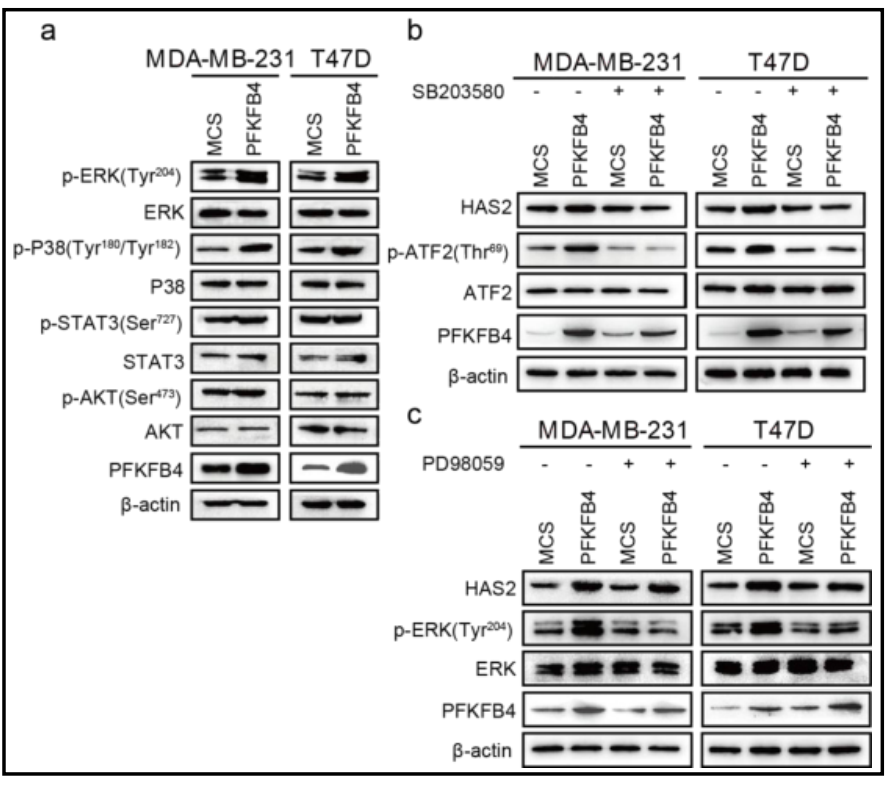
HAS2 expression does not increase in PFKFB4 MDA-MB-231 and T47D cells versus MCS cells. ATF2 is a downstream molecule of P38 and phosphorylated by P38. $\beta$-actin serves as a loading control. (c) Western blot analysis of HAS2 expression. This western blot qualitatively shows that HAS2 expression increases in PFKFB4 MDA-MB-231 and T47D cells both in the absence (-) and presence $(+)$ of ERK inhibitor PD98059 versus MCS cells. $\beta$-actin serves as a loading control. Data are representatives of at least three independent experiments.

PFKFB4 ectopic expression enhances ERK phosphorylation and p38 phosphorylation, but does not affect STAT3 phosphorylation or Akt phosphorylation in MDA-MB-231 and T47D breast cancer cells versus control (Fig. 9a). In order to examine whether the activated ERK and p38 signaling pathways are associated with the PFKFB4-induced up-regulation of HAS2, we treated PFKFB4-ectopically expressed MDA-MB-231 and T47D cells with either a pharmacological inhibitor of ERK (i.e., PD98059) or a pharmacological inhibitor of p38 (i.e., SB203580) and measured HAS2 expression. We found that SB203580-treatment (i.e., p38 inhibition) reduces HAS2 expression in PFKFB4-ectopically expressed MDA-MB-231 and T47D cells versus untreated controls, but SB203580-treatment does not affect basal levels of HAS2 expression (Fig. 9b). In contrast, we found that PD98059-treatment (i.e., ERK inhibition) does not affect HAS2 expression in PFKFB4-ectopically expressed MDAMB-231 and T47D cells versus untreated controls (Fig. 9c). In addition, we observed that SB203580-treatment (i.e., p38 inhibition) eliminates the elevated migration capacity in PFKFB4-ectopically expressed MDA-MB-231 and T47D cells versus controls (Fig. 10a-d). The above-mentioned results collectively suggest that the PFKFB4-induced up-regulation of HAS2 depends on the phosphorylation of p38.

\section{Discussion}

PFKFB4 is induced by hypoxia in multiple cancer cell lines and is also highly expressed in matched human lung, breast and colon tumor tissues versus normal tissues from the same patients both of which indicate a potential role in cancer initiation and/or progression [1720]. In this study, we found that PFKFB4 promotes breast cancer migration/invasion via a novel pathway i.e., PFKFB4/p38/HAS2 (HA). PFKFB4 overexpression phosphorylates p38 and activates unidentified downstream transcription factors that initiate HAS2 transcription and expression. This leads to HA accumulation in the tumor micro-environment and thereby creates a pro-metastatic micro-environment (Fig. 11). PFKFB bi-functional enzymes are encoded by 4 genes (i.e., PFKFB1, PFKFB2, PFKFB3 and PFKFB4) of which PFKFB3 and PFKFB4 are particularly under extensive investigation. PFKFB3 and PFKFB4 expression increases in malignant tumors and plays a significant role in tumor cell proliferation and 
Fig. 10. PFKFB4-induced breast cancer cell migration depends on $\mathrm{p} 38$ phosphorylation. (a) Transwell assay of migrated cells. This graph shows that in control group (SB203580-), the number of migrated cells increases in PFKFB4 MDA-MB-231 cells versus MCS cells $\left(219 \pm 12\right.$ vs $115 \pm 10$, respectively; $\left.{ }^{* * *} \mathrm{P}<0.001\right)$. In the presence of SB203580 (SB203580+), the number of migrated cells does not increase in PFKFB4 MDA-MB- 231 cells versus MCS cells ( $83 \pm 7$ vs $72 \pm 8$, respectively; NS). (b) Wound healing assay of migrated distance. This graph shows that in control group (SB203580-), the migrated distance increases in PFKFB4 MDA-MB-231 cells versus MCS cells $\left(1969 \pm 83.2\right.$ vs $1203 \pm 132.7$, respectively; $\left.{ }^{* * *} \mathrm{P}<0.001\right)$. In the presence of SB203580 (SB203580+), the migrated distance does not increase in PFKFB4 MDA-MB-231 cells versus MCS cells $(1370 \pm 108.6$ vs $1182 \pm 126.5$, respectively; NS). (c) Transwell assay of migrated cells. This graph shows that in control group (SB203580-), the number of migrated cells increases in PFKFB4 T47D cells versus MCS cells $(206 \pm 10$ vs $113 \pm 7$, respectively; ${ }^{* * *} \mathrm{P}<0.001$ ). In the presence of SB203580 (SB203580+), the number of migrated

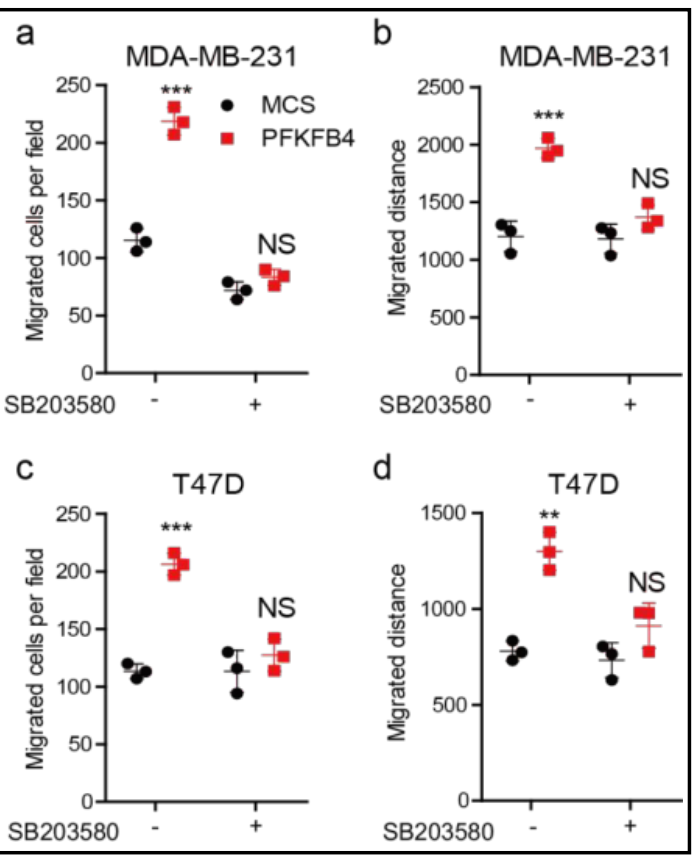
cells does not increase in PFKFB4 T47D cells versus

MCS cells (127 \pm 14 vs $113 \pm 18$, respectively; NS). (d) Wound healing assay of migrated distance. This graph shows that in control group (SB203580-), the migrated distance increases in PFKFB4 T47D cells versus MCS cells $\left(1300 \pm 99.1\right.$ vs $780 \pm 51.3$, respectively; $\left.{ }^{* *}<<0.01\right)$. In the presence of SB203580 (SB203580+), the migrated distance does not increase in PFKFB4 T47D cells versus MCS cells $(912.0 \pm 116.9$ vs $733.0 \pm 91.3$, respectively; NS). Data are shown as mean \pm SD; One-way ANOVA was used for statistical analysis; NS= not significant; Data are representatives of at least three independent experiments.

Fig. 11. A proposed model for the PFKFB4/p38/HAS2/HA pathway promotion of migration/invasion in breast cancer cells. In our proposed model, PFKFB4 expression in a breast cancer cell up-regulates p38 phosphorylation (Step 1). The activated p38 signaling increases downstream HAS2 transcription and HAS2 expression (Step 2). The increased HAS2 transcription and HAS2 expression elevates HA accumulation in the extracellular matrix (Step 3). The elevated HA accumulation promotes breast cancer cell migration/invasion (Step 4).

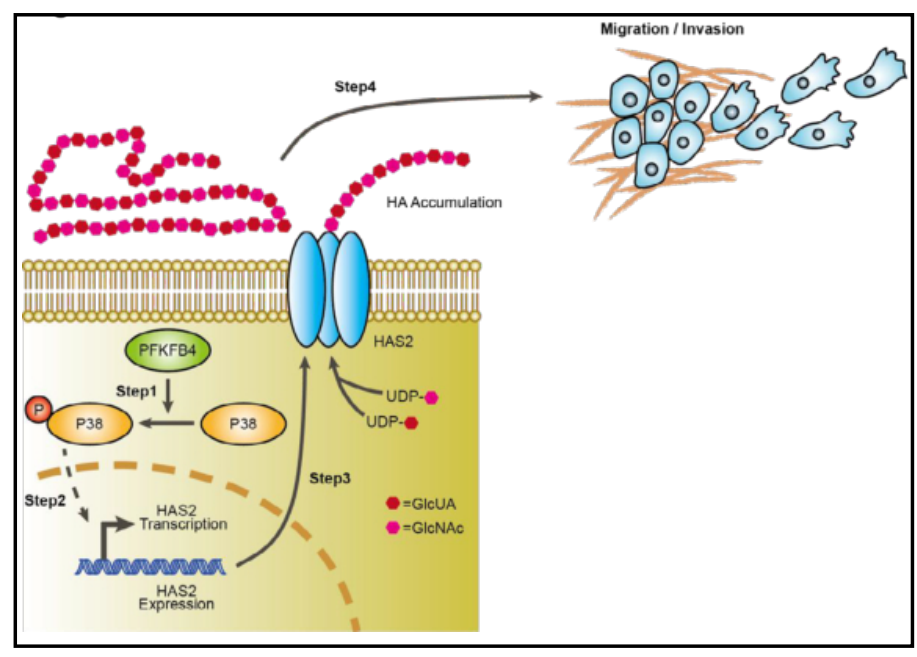

survival. In addition, PFKFB3 plays a role in tumor metastasis in head and neck squamous cell carcinoma and nasopharyngeal carcinoma [36, 37]. Previous reports indicate that HA accumulation occurs in numerous tumor types and thereby facilitates the progression and metastasis of carcinomas [38, 39]. In addition, HAS2 synthesizes HA (HMW-HA in particular) in a prolific fashion in tumors [27]. Consequently, therapeutic strategies that may either inhibit HAS2 expression or reduce HA accumulation in the tumor micro-environment in order to prevent tumor migration/invasion are of relevant interest.

Several factors and signaling pathways play a role in HAS2 induction. In this regard, epidermal growth factor (EGF) increases HAS2 and HAS3 expression and thereby induces HA synthesis [40]. Platelet-derived growth factor (PDGF)-BB increases HAS2 expression through 


\section{Cellular Physiology Cell Physiol Biochem 2018;50:2108-2123 \begin{tabular}{l|l|l} 
and Biochemistry Published online: 10 November 2018 & $\begin{array}{l}\text { (c) } 2018 \text { The Author(s). Published by S. Karger AG, Basel } \\
\text { www.karger.com/cpb }\end{array}$ \\
\hline
\end{tabular} \\ Gao et al.: PFKFB4 Promotes Breast Cancer Metastasis}

the activation of phosphatidylinositol 3-kinase (PI3K) and mitogen-activated/extracellular signal-regulated kinase (MEK) [41]. UTP increases the phosphorylation of p38, ERK, and Ser-727 of STAT3 in human keratinocytes. p38, ERK, and STAT3 inhibitors partially block the activation of HAS2 expression which confirms the involvement of these pathways in the UTP-induced HAS2 response [42]. In this study, we found that PFKFB4 induces p38 and ERK phosphorylation, but not STAT3 or Akt phosphorylation. However, only PFKFB4-induced p38 phosphorylation (not ERK phosphorylation) elicits HAS2 expression and thereby contributes to tumor cell migration/invasion. p38 is activated by extracellular stress stimuli (e.g., UV light, heat, inflammatory cytokines, and growth factors). The p38 activation involves either a MAP kinase kinase (MAPKKs)-dependent mechanism or a MAPKK-independent mechanism [43]. We found that PFKFB4 overexpression increases glucose uptake and lactate secretion which facilitates glycolysis for glucose metabolism (unpublished data). The carbohydrate metabolism change in the microenvironment generates a stress stimulus to tumor cells that cause p38 activation. In addition, previous reports observed that TLR4-stimulated glycolysis involves a p38 MAPK-dependent HIF-1a accumulation in human monocyte-derived DCs [44]. However, p38 activation by glycolysis via a MAPKK-dependent or MAPKK-independent mechanism needs further investigation.

The precursor substrates of HA include UDP-glucuronic acid and UDP-Nacetylglucosamine both of which use glucose as the original synthetic source [24]. Our previous studies showed that PFKFB4 overexpression not only increases glucose uptake and lactate secretion but also decreases ROS levels which suggests that PFKFB4 overexpression shifts glucose metabolism from oxidative phosphorylation to glycolysis (data not shown). However, the role of other glucose metabolic pathways (e.g., the hexosamine signaling pathway) which generate UDP-N-acetylglucosamine remain unexamined. This infers that PFKFB4 may also assist HA synthesis through other metabolic pathways which provides an area of future investigation.

Previous investigations have shown that both SB203580 (a p38 MAPK inhibitor) and 4-methylumbelliferone (4-MU; a HA inhibitor) suppress tumor cell migration/invasion in gastric, lung, breast, and pancreatic cancers [45-49]. However, due to the limited efficacy of these inhibitors clinical trials have not been initiated. In this regard, Jason et al., reported that 5-(n-(8-methoxy-4-quinolyl) amino) pentyl nitrate (5MPN; a newly designed selective PFKFB4 inhibitor) suppresses proliferation of multiple human tumor cell lines but not non-transformed epithelial cells in vitro [22]. However, the effect of 5MPN on tumor cell migration/invasion remains unexamined and provides a fertile area for future investigation. Furthermore, the effect of various combinations of the above-mentioned inhibitors on tumor cell migration/invasion based on the PFKFB4/p38/HAS2 (HA) pathway described in this study also provides a fertile area for future investigation.

\section{Conclusion}

In conclusion, our results demonstrate that PFKFB4 enhances the invasiveness of breast cancer cells in vitro and in vivo by inducing HA production. Moreover, PFKFB4-induced expression of HAS2 depends upon the activation of p38 signaling. This leads us to propose that PFKFB4, p38, and HAS2 may serve as therapeutic targets in the treatment of breast cancer.

\section{Acknowledgements}

This work was supported by National Natural Science Foundation of China 81301856 $(\mathrm{NL})$, the S\&T plan project of Tianjin (12JCYBJC30900) and Tianjin Research Program of Application Foundation and Advanced Technology 15JCQNJC11700.

\section{Disclosure Statement}

The authors declare no potential conflicts of interest. 


\section{Cellular Physiology Cell Physiol Biochem 2018;50:2108-2123 and Biochemistry Published \begin{tabular}{l|l} 
DOI: 10.1159/000495055 & $\begin{array}{l}\text { (c) } 2018 \text { The Author(s). Published by S. Karger AG, Basel } \\
\text { www.karger.com/cpb }\end{array}$
\end{tabular}}

Gao et al.: PFKFB4 Promotes Breast Cancer Metastasis

\section{References}

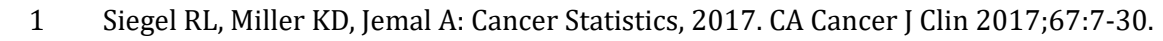

-2 Zeichner SB, Stanislaw C, Meisel JL: Prevention and Screening in Hereditary Breast and Ovarian Cancer. Oncology (Williston Park) 2016;30:896-904.

- 3 Hue TF, Cummings SR, Cauley JA, Bauer DC, Ensrud KE, Barrett-Connor E, Black DM: Effect of bisphosphonate use on risk of postmenopausal breast cancer: results from the randomized clinical trials of alendronate and zoledronic acid. JAMA Intern Med 2014;174:1550-1557.

-4 Jatoi I: Bilateral Mastectomy for Unilateral Breast Cancer: a Perplexing Trend. Indian J Surg Oncol 2015;6:387-389.

5 DeSantis CE, Lin CC, Mariotto AB, Siegel RL, Stein KD, Kramer JL, Alteri R, Robbins AS, Jemal A: Cancer treatment and survivorship statistics, 2014. CA Cancer J Clin 2014;64:252-271.

6 Hockel M, Vaupel P: Tumor hypoxia: definitions and current clinical, biologic, and molecular aspects. J Natl Cancer Inst 2001;93:266-276.

7 Ratcliffe PJ, O’Rourke JF, Maxwell PH, Pugh CW: Oxygen sensing, hypoxia-inducible factor-1 and the regulation of mammalian gene expression. J Exp Biol 1998;201:1153-1162. Hsu PP, Sabatini DM: Cancer cell metabolism: Warburg and beyond. Cell 2008;134:703-707. Vander Heiden MG, Cantley LC, Thompson CB: Understanding the Warburg effect: the metabolic requirements of cell proliferation. Science 2009;324:1029-1033.

10 Hanahan D, Weinberg RA: Hallmarks of cancer: the next generation. Cell 2011;144:646-674.

11 Crepin KM, Darville MI, Hue L, Rousseau GG: Characterization of distinct mRNAs coding for putative isozymes of 6-phosphofructo-2-kinase/fructose-2, 6-bisphosphatase. Eur J Biochem 1989;183:433-440.

12 Pilkis SJ, Claus TH, Kurland IJ, Lange AJ: 6-Phosphofructo-2-kinase/fructose-2, 6-bisphosphatase: a metabolic signaling enzyme. Annu Rev Biochem 1995;64:799-835.

13 Hue L, Beauloye C, Bertrand L, Horman S, Krause U, Marsin AS, Meisse D, Vertommen D, Rider MH: New targets of AMP-activated protein kinase. Biochem Soc Trans 2003;31:213-215.

14 Okar DA, Manzano A, Navarro-Sabate A, Riera L, Bartrons R, Lange AJ: PFK-2/FBPase-2: maker and breaker of the essential biofactor fructose-2, 6-bisphosphate. Trends Biochem Sci 2001;26:30-35.

15 Sakata J, Abe Y, Uyeda K: Molecular cloning of the DNA and expression and characterization of rat testes fructose-6-phosphate,2-kinase:fructose-2, 6-bisphosphatase. J Biol Chem 1991;266:15764-15770.

-16 Manzano A, Perez JX, Nadal M, Estivill X, Lange A, Bartrons R: Cloning, expression and chromosomal localization of a human testis 6-phosphofructo-2-kinase/fructose-2, 6-bisphosphatase gene. Gene 1999;229:83-89.

17 Minchenko OH, Opentanova IL, Ogura T, Minchenko DO, Komisarenko SV, Caro J, Esumi H: Expression and hypoxia-responsiveness of 6-phosphofructo-2-kinase/fructose-2, 6-bisphosphatase 4 in mammary gland malignant cell lines. Acta Biochim Pol 2005;52:881-888.

18 Minchenko OH, Ochiai A, Opentanova IL, Ogura T, Minchenko DO, Caro J, Komisarenko SV, Esumi H: Overexpression of 6-phosphofructo-2-kinase/fructose-2, 6-bisphosphatase-4 in the human breast and colon malignant tumors. Biochimie 2005;87:1005-1010.

19 Minchenko OH, Ogura T, Opentanova IL, Minchenko DO, Ochiai A, Caro J, Komisarenko SV, Esumi H: 6-Phosphofructo-2-kinase/fructose-2, 6-bisphosphatase gene family overexpression in human lung tumor. Ukr Biokhim Zh (1999) 2005;77:46-50.

20 Minchenko 0, Opentanova I, Caro J: Hypoxic regulation of the 6-phosphofructo-2-kinase/fructose-2, 6-bisphosphatase gene family (PFKFB-1-4) expression in vivo. FEBS Lett 2003;554:264-270.

21 Goidts V, Bageritz J, Puccio L, Nakata S, Zapatka M, Barbus S, Toedt G, Campos B, Korshunov A, Momma S, Van Schaftingen E, Reifenberger G, Herold-Mende C, Lichter P, Radlwimmer B: RNAi screening in glioma stem-like cells identifies PFKFB4 as a key molecule important for cancer cell survival. Oncogene 2012;31:3235-3243.

22 Chesney J, Clark J, Lanceta L, Trent JO, Telang S: Targeting the sugar metabolism of tumors with a first-inclass 6-phosphofructo-2-kinase (PFKFB4) inhibitor. Oncotarget 2015;6:18001-18011.

-23 Ros S, Santos CR, Moco S, Baenke F, Kelly G, Howell M, Zamboni N, Schulze A: Functional metabolic screen identifies 6-phosphofructo-2-kinase/fructose-2, 6-biphosphatase 4 as an important regulator of prostate cancer cell survival. Cancer Discov 2012;2:328-343.

24 Dicker KT, Gurski LA, Pradhan-Bhatt S, Witt RL, Farach-Carson MC, Jia X: Hyaluronan: a simple polysaccharide with diverse biological functions. Acta Biomater 2014;10:1558-1570.

25 Laurent TC, Fraser JR: Hyaluronan. Faseb j 1992;6:2397-2404.

-26 Spicer AP, McDonald JA: Characterization and molecular evolution of a vertebrate hyaluronan synthase gene family. J Biol Chem 1998;273:1923-1932. 


\section{Cellular Physiology Cell Physiol Biochem 2018;50:2108-2123

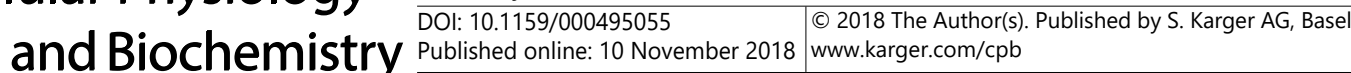 \\ Published online: 10 November 2018 www.karger.com/cpb}

-27 Tian X, Azpurua J, Hine C, Vaidya A, Myakishev-Rempel M, Ablaeva J, Mao Z, Nevo E, Gorbunova V, Seluanov A: High-molecular-mass hyaluronan mediates the cancer resistance of the naked mole rat. Nature 2013;499:346-349.

28 Csoka AB, Scherer SW, Stern R: Expression analysis of six paralogous human hyaluronidase genes clustered on chromosomes 3p21 and 7q31. Genomics 1999;60:356-361.

-29 Toole BP: Hyaluronan in morphogenesis. Semin Cell Dev Biol 2001;12:79-87.

-30 Itano N, Kimata K: Altered hyaluronan biosynthesis in cancer progression. Semin Cancer Biol 2008;18:268274.

31 Costea DE, Hills A, Osman AH, Thurlow J, Kalna G, Huang X, Pena Murillo C, Parajuli H, Suliman S, Kulasekara KK, Johannessen AC, Partridge M: Identification of two distinct carcinoma-associated fibroblast subtypes with differential tumor-promoting abilities in oral squamous cell carcinoma. Cancer Res 2013;73:3888-3901.

32 Berdiaki A, Nikitovic D, Tsatsakis A, Katonis P, Karamanos NK, Tzanakakis GN: bFGF induces changes in hyaluronan synthase and hyaluronidase isoform expression and modulates the migration capacity of fibrosarcoma cells. Biochim Biophys Acta 2009;1790:1258-1265.

-33 Ween MP, Oehler MK, Ricciardelli C: Role of versican, hyaluronan and CD44 in ovarian cancer metastasis. Int J Mol Sci 2011;12:1009-1029.

-34 Arai E, Nishida Y, Wasa J, Urakawa H, Zhuo L, Kimata K, Kozawa E, Futamura N, Ishiguro N: Inhibition of hyaluronan retention by 4-methylumbelliferone suppresses osteosarcoma cells in vitro and lung metastasis in vivo. Br J Cancer 2011;105:1839-1849.

-35 Yoshihara S, Kon A, Kudo D, Nakazawa H, Kakizaki I, Sasaki M, Endo M, Takagaki K: A hyaluronan synthase suppressor, 4-methylumbelliferone, inhibits liver metastasis of melanoma cells. FEBS Lett 2005;579:27222726.

-36 Li HM, Yang JG, Liu ZJ, Wang WM, Yu ZL, Ren JG, Chen G, Zhang W, Jia J: Blockage of glycolysis by targeting PFKFB3 suppresses tumor growth and metastasis in head and neck squamous cell carcinoma. J Exp Clin Cancer Res 2017;36:7.

-37 Gu M, Li L, Zhang Z, Chen J, Zhang W, Zhang J, Han L, Tang M, You B, Zhang Q, You Y: PFKFB3 promotes proliferation, migration and angiogenesis in nasopharyngeal carcinoma. J Cancer 2017;8:3887-3896.

-38 Turley EA, Noble PW, Bourguignon LY: Signaling properties of hyaluronan receptors. J Biol Chem 2002;277:4589-4592.

-39 Toole BP: Hyaluronan: from extracellular glue to pericellular cue. Nat Rev Cancer 2004;4:528-539.

40 Pasonen-Seppanen S, Karvinen S, Torronen K, Hyttinen JM, Jokela T, Lammi MJ, Tammi MI, Tammi R: EGF upregulates, whereas TGF-beta downregulates, the hyaluronan synthases Has2 and Has3 in organotypic keratinocyte cultures: correlations with epidermal proliferation and differentiation. J Invest Dermatol 2003;120:1038-1044.

41 Li L, Asteriou T, Bernert B, Heldin CH, Heldin P: Growth factor regulation of hyaluronan synthesis and degradation in human dermal fibroblasts: importance of hyaluronan for the mitogenic response of PDGFBB. Biochem J 2007;404:327-336.

-42 Jokela T, Karna R, Rauhala L, Bart G, Pasonen-Seppanen S, Oikari S, Tammi MI, Tammi RH: Human Keratinocytes Respond to Extracellular UTP by Induction of Hyaluronan Synthase 2 Expression and Increased Hyaluronan Synthesis. J Biol Chem 2017;292:4861-4872.

43 Zarubin T, Han J: Activation and signaling of the p38 MAP kinase pathway. Cell Res 2005;15:11-18.

-44 Perrin-Cocon L, Aublin-Gex A, Diaz O, Ramiere C, Peri F, Andre P, Lotteau V: Toll-like Receptor 4-Induced Glycolytic Burst in Human Monocyte-Derived Dendritic Cells Results from p38-Dependent Stabilization of HIF-1alpha and Increased Hexokinase II Expression. J Immunol 2018;10.4049/jimmunol.1701522.

45 Ma XM, Shen ZH, Liu ZY, Wang F, Hai L, Gao LT, Wang HS: Heparanase promotes human gastric cancer cells migration and invasion by increasing Src and p38 phosphorylation expression. Int J Clin Exp Pathol 2014;7:5609-5621.

46 Liang H, Gu M, Yang C, Wang H, Wen X, Zhou Q: Sevoflurane inhibits invasion and migration of lung cancer cells by inactivating the p38 MAPK signaling pathway. J Anesth 2012;26:381-392.

47 Yang Y, Cheon S, Jung MK, Song SB, Kim D, Kim HJ, Park H, Bang SI, Cho D: Interleukin-18 enhances breast cancer cell migration via down-regulation of claudin-12 and induction of the p38 MAPK pathway. Biochem Biophys Res Commun 2015;459:379-386.

48 Cao L, Chen X, Xiao X, Ma Q, Li W: Resveratrol inhibits hyperglycemia-driven ROS-induced invasion and migration of pancreatic cancer cells via suppression of the ERK and p38 MAPK signaling pathways. Int J Oncol 2016;49:735-743.

49 Nagy N, Kuipers HF, Frymoyer AR, Ishak HD, Bollyky JB, Wight TN, Bollyky PL: 4-methylumbelliferone treatment and hyaluronan inhibition as a therapeutic strategy in inflammation, autoimmunity, and cancer. Front Immunol 2015;6:123. 